\title{
The Concept, Influencing Factor and Development Model of New Real Economy: Experience Learned at Home and Abroad
}

\author{
Hang WU \\ Business School, East China University of Political Science and Law, Shanghai 201620, China \\ wuhang0503@163.com
}

Keywords: New real economy, Influencing factor, Development model.

\begin{abstract}
Existing research has not obviously uncovered the concept, influencing factor and development model of new real economy. This paper argues that the new real economy should be a high integration of the internet, virtual economy and real economy and affected by consumption and scientific and technological innovation. The former is characterized by consumer personalization, consumer integration and consumer facilitation, and the latter refers to new technologies for basic industries and core intelligent manufacturing technology. Experience learned at home and abroad shows that, in order to develop new real economy, the government should create personalized custom direct marketing platform, promote service transformation of manufacturing enterprises, and play the guiding role of industry funds.
\end{abstract}

\section{Introduction}

After tens of year's development, China's real economy has made great success and improved people's living conditions[1]. However, there are still a lot of problem in China's real economy. First, a lot of SMEs face the financing difficulties and high tax burden. Second, industry as a whole is still in the low-end chain, focusing on textiles, clothing, metal rolling and other labor-intensive, low-tech products, low added value links[2]. Third, The number of large enterprises and large groups is small, and corporate governance model needs to be further improved. At last, the short board of innovation ability is obvious, and industry core competitiveness is not strong[3]. In view of this, it is necessary to develop new real economy and integrate internet with real economy.

\section{The Concept of the New Real Economy}

The new real economy (also called the new economy), is an economic concept put forward by the Alibaba Group Chairman Ma. Ma argues that the new real economy, referring to the Internet and traditional economic integration, together to create future economic forms, through technological innovation, model innovation to form a new real economy. The new real economy is new forms of economy generated by the combination of traditional industries and the Internet[4]. There is a strong interdependence, absolutely not completely antagonistic relationship between traditional industries and the Internet. Therefore, the correct way to resolve the contradiction should be to promote the integration of old and new economic, transform old into new[5]. Through the Internet technology, we can enhance the traditional industries, and even use the original elements of resources to create new industries.

As Alibaba Chairman Ma in the second World Conference on the Internet reporting to Xi Jinping Chairman that new economy equals the plus of new consumption and new real. On the one hand, the traditional enterprises, especially a large number of SMEs can make use of the services provided by the Internet companies to improve efficiency, transform into a new real. On the other hand, the traditional disadvantaged industries, such as agriculture, can use the network to achieve industrialization. All along, the information and logistics is the two stumbling block of the agricultural industrialization, and these two points is the advantage of electricity providers, with the Internet can make a large number of traditional farmers into industrial farmers in recent years, some places emerged "Taobao Village" is this embodiment of exploration. 
At March 16, 2016, Premier Li Keqiang points out at the Fourth Session of the 12th National People's Congress, the coverage and connotation of new economy are very broad. It involves the first, second and third industry, not only refers to the "Internet +", Internet of things, cloud computing, e-commerce in the third industry, but also includes such manufacturing industry as intelligent manufacturing, large-scale customized production, and also related to a production which is conducive to promoting the appropriate scale of the family farms, stock cooperative system. Moreover, for the development of "new economy", small and micro enterprises can accomplish much, large enterprises can have more [6]. At present, many large enterprises are engaged in innovator space, and there are many such examples.

Chen Wenling argues that the world economy today formed two basic economic forms, one is the real economy, one is the virtual economy, and the two interrelated and evolved as an endogenous factor in changing the old economic form. Internet will integrate two forms of economic form, and form a new real economy. However, the Internet can not be considered as a virtual economy, the Internet is only a technical means which lead to changes in the real economy. And this new real economic form is the interaction of the virtual economy and real economy. At present, the world economy has emerged as a new economic form, which has evolved from the real economy as the mainstay of the industrialization times into information age constituted by the real economy and fictitious economy. Social form and superstructure are undergoing a great remodeling, together constitute the information age economic and social transformation[7]. The old systems, rules, values and economic patterns are shaken and evolving, and new systems, rules and economic forms are being reconstructed or generated.

Thus, the current concept of the new real economy is far from a unified definition[8]. Ma stressed that the new real economy is a new form of economy and a combination of traditional industries and the Internet, emphasizing the small and medium enterprises hit the wire shocks. Premier Li Keqiang further stressed that the new real economy is the emerging industries and formats based on the Internet, and the depth integration of Internet and traditional economy, involving the first, second and third industries. Chen Wenling stressed that the new real economy is the links and interaction of Internet, virtual economy, real economy, emphasizing the depth change of Internet on the manufacturing industry, trade, service formats, agricultural formats, large data formats, but did not point out how the virtual economy to serve the development of the real economy. Therefore, the new real economy should be a high integration of the Internet, virtual economy and real economy.

\section{Factors Affecting the Development of the New Real Economy}

\section{Consumption}

From the medium and long term, the impacting factor of the new real economy is consumption. All the operation aim of real economy is, in fact, to meet the consumption of residents. With the economic and social development and income growth, consumer demand is constantly changing. Specifically, the performance is manifested as the following three characteristics. The first is consumer personalization which means that fully in accordance with consumer preferences to consumer trends[9]. This trend is not appeared after 20 years, but now have, especially in the relatively high income groups. This trend is precisely the ultimate needs of mankind, so as to achieve real satisfaction. The second is consumer integration which means that consumers want to get a package solution, rather than traveling and toil. This change in consumer trends will continue to exist from now to the future, which is resulting from the concept of integrator. The third is consumer facilitation which means that consumers are certainly willing to minimize the physical and economic costs, making the maximum consumer benefits. Consuming more and more convenient is the instinct of consumers. In such a trend, all the technical changes, production patterns, business models are changing. 


\section{Scientific and Technological Innovation}

China is now at a turning point in major scientific and technological innovations and technological revolutions. Germany began to industrial 4.0, the United States CPS are showing that they are preparing a new production model and business model to adapt to the previously mentioned changes in consumer demand. The development of the new real economy will inevitably accompanied by the emergence of certain scientific and technological innovation. The first is new technologies for basic industries. This constitutes manufacturing equipment, technology and product base of a new real economy. Information, large data analysis technology, new energy, new materials technology, will also bring a series of major changes in the basic industry.

The second is core intelligent manufacturing new technology to form a new type of production service system, such as smart assembly, embedded electronics, intelligent systems and software control, intelligent custom production and online control systems, resources and products, service delivery, technology and more. Now the Internet is mainly through the communication between people, from the service areas related to the production area. The future of the new real economy, may be intelligent manufacturing era, such as machine and machine interconnection, the machine interconnection controlled through the virtual control system, which is the core of industry 4.0 and CPS. The machine learns, exchanges, completes the manufacture and service according to our requirements.

\section{Model 1: Create Personalized Custom Direct Marketing Platform}

With the development of Internet technology, the traditional business model of manufacturing enterprises appeared certain defects. One the one hand, because the manufacturers put the cost of inventory, channels and shopping malls and other intermediaries fare on consumers, thus promote the product price. One the other hand, the trend of personalized demand of consumers and convenience of consumption challenges the traditional business model. Personalized customization platform will put manufacturers and customers on the same platform, which rapidly collects customers scattered, personalized demand data at the same time, eliminates the traditional intermediate circulation caused by the information asymmetry and all kinds of agency costs, greatly reducing the transaction cost.

A typical case is the consumer demand direct business platform of the Red collar group. Red collar group is founded in 1995, a large enterprises in Qingdao for production and operation of high-end suits, pants, shirts, casual wear and apparel products. With information technology, Red collar successfully launches the global personalized custom platform - the global custom clothing supplier platform, after hundreds of millions of capital investment. Red collar self-developed online customized direct marketing platform-C2M platform is the user's online portal to support multi-category and multi-product online customization. Consumers login through the computer, mobile phones and other information terminal, online choose product style, process, raw materials, online pay after the generation of orders, really realizing the whole process of data-driven and network operation from product customization, trading, payment, design, production process, production process, post-processing to logistics, after-sales service. After the customer orders, the factory begins the production, so there is no funds and goods backlog, really achieving "on-demand production, zero inventory", and maximizing the benefits to consumers, and consumers no longer share the cost of business. Custom manufacturing costs only $10 \%$ higher than the volume manufacturing, but the revenue was able to achieve more than twice.

\section{Model 2: Promote Service Transformation of Manufacturing Enterprises}

Compared with the traditional manufacturing model, service-oriented manufacturing model achieve the four changes: from the product as the market competition center to provide services around the main products; from the pyramid-based organizational structure to the matrix-type organizational structure changes; from the one-time transaction earnings of product delivery to services profit to the cyclical phase; from the impact of economic fluctuations to a strong economic resilience to change. According to the transformation experience of the leading manufacturing enterprises in Europe and 
America, there are two transformation modes to excavate customer value and provide service business along the value chain.

Firstly, firms provide the scalable service mode based on traditional superior products. Europe and the United States leading manufacturers provide products based on customer service to improve customer satisfaction, and thus achieve customer loyalty. The second is to put operational management knowledge as the core and provide professional services. Unlike traditional services, this phase of the service is no longer rely on their original products, but the manufacturing enterprise-leading supply chain, operations management, R \& D management knowledge as the core output to other enterprises. The revenue source of the model is no longer the product sales, but professional service management costs and labor costs.

Prior to the 1990s, civil jet engines contained more than 10000 components, and each engine was dismantled every five years for full repairs. The cost is more than one million US dollars, while the aircraft's engine structure is extremely complex, poor use of the environment makes the aircraft engine vulnerable to damage. Therefore, the maintenance costs during use of the aircraft engine is much higher than the cost of buying the aircraft engines. And most of the airlines are invested huge amounts of money to establish aircraft maintenance facilities and aircraft parts supply chain management department to protect the aircraft in good condition. Into the 90's, the airlines are facing increasingly fierce competitive pressures, can no longer afford the high cost of aircraft maintenance, can't wait to find ways to shake off this burden.

After fully understanding the needs of customers, Rolls-Royce began to set up a new service support system and continue to extend the service value chain, launched a comprehensive maintenance services. Comprehensive maintenance services for airlines provides a set of after-sales service program, not only contains the traditional maintenance services, but also incorporates new value-added services, and form a modular package of service packages. In this way, excellent data analysis, a mature supply chain system, excellent cost control and the world's leading technology, allows Rolls-Royce to provide customers with high-performance engine products, and minimize the potential failure of the band and help customers achieve risk transfer.

Another example is the network management service transformation model of Ericsson. Entering the 21st century, rapid technological change has prompted telecom operators and TV broadcast media operators to re-examine their position in the value chain, focusing on business and customer value realization. For operators, the construction and management of complex communication networks is a challenging, time-consuming and resource-intensive work. In contrast, operators are more willing to focus on improving the market share and brand awareness and other core business. Based on their rich knowledge accumulated over the years, Ericsson has built a complete set of end-to-end management service solutions based on the needs of operators to outsource the management of communication network services. The management services include communications network management services, IT management services, radio and television management services and network sharing services. Ericsson has successfully completed the upgrade of its business structure from a product equipment suppliers to a full-service solution provider and a transition to service delivery.

\section{Model 3: Play the Guiding Role of Industry Funds}

As the subsidies of new energy vehicles lag in time, the key for the realization of electric vehicle project implementation is to solve the liquidity problem. Ninghai County firmly grasps the main contradiction, not fights the policy but fights mode, finally solves the project liquidity problem through the establishment of fixed investment funds. Investment Fund will be invested by the Ninghai County about 600 million yuan, Jinsha River Venture Capital about 1.4 billion through bank financing, finally establishing the total size of 2 billion government-led industry fund (Silverstone Fund). Silverstone Fund adopts the "equity + debt" fixed investment approach, introducing equity and debt into the project through the two ways. Among this, 400 million yuan of funds can obtain $10 \%$ stake, the remaining 1.6 billion injects into the project in accordance with the shareholders borrowing channels, which not only solves the major shareholder control problem, but also meets the 
demand for return of the bank funds. At the same time, the fund shares the implementation of "priority + bad after" equity income approach. Government and bank funds have priority access to stable income and to ensure the safety of the principal. Venture capital companies bear the responsibility of the risk, and at the same time enjoy the risk of capital premium. As a result of establishing a perfect balance of interests mechanism, the investors reached a smooth consensus, creating a miracle from the initial contact to the project settled costing only 113 days.

\section{Conclusion}

Existing research has not obviously uncovered the concept, influencing factor and development model of new real economy. This paper argues that the new real economy should be a high integration of the internet, virtual economy and real economy and affected by consumption and scientific and technological innovation. The former is characterized by consumer personalization, consumer integration and consumer facilitation, and the latter refers to new technologies for basic industries and core intelligent manufacturing new technology. Experience learned at home and abroad shows that, in order to develop new real economy, the government should create personalized custom direct marketing platform, promote service transformation of manufacturing enterprises, and play the guiding role of industry funds.

\section{Acknowledgement}

This research was financially supported by the National Natural Science Foundation of China (71502064).

\section{References}

[1] Y. Zhou, C. Liu, Coupling effects of Chinese fictitious economy and real economy, Journal of Shanxi Finance and Economics University, 33 (2011) 10-19.

[2] X. Ye, Z. Yan, Interactions between virtual economy and real economy: A perspective from international industrial transfer, Social Sciences in China, 9 (2012) 63-81.

[3] J. Liu, C. Wu, A Model of Fictitious Economy and Real Economy-An Explanation of Chinese Stock Market Deviating from Real Economy, Economic Research Journal, 4 (2004) 60-69.

[4] C. Wen, G. Ren, Research on seperating development of virtual and substantial economy-Evidence from China's listed firms from 2006 to 2013, China Industrial Economics, 12(2015)115-129.

[5] Y. Li, Y. Han, Mechanism analysis of the evolution of the financial economy on real economic growth-Perspectives of the capital allocation, China Industrial Economics, 2(2011)26-35.

[6] Y. Xiao, Y. Ni, Z. Fang, Empirical study on the nexus among stock price, real economy and monetary policy: Based on China's data from 1997 to 2011, Economic Review, 2(2012)97-104.

[7] M. Lu, T. Wang, The negative impact of interest rate marketization on the real economy and countermeasures, Finance \& Economics, 6(2014)1-11.

[8] M. Lu, Effective Analysis of Finance's Support of China's Real Economy, Finance \& Economics, 6(2013)1-9.

[9] Y. Wang, X. Gao, Z. Yuan, J. Du, Financial development, asset bubble and the real economy: A survey, Journal of Financial Research, 5(2015)191-206. 